Int. J. Electrochem. Sci., 12 (2017) 3040 - 3049

\title{
Electrochemical Analysis of Ki67 Protein As Pancreatic Cancer Biomarker Based on Graphene-Polydopamine Nanocomposite
}

\author{
Liguo Hao ${ }^{1,2 *}$, Lijie Liu $^{3}$, Xin Meng ${ }^{4}$, Hongsheng Cui ${ }^{4}$, Zixu Wang ${ }^{1}$ \\ ${ }^{1}$ 1.Medical Technology School of Qiqihar Medical University, No. 333 Bukui North Road, Jianhua \\ District, Qiqihar City, Heilongjiang Province 161006, P.R. China \\ ${ }^{2}$ Academy of Medical Sciences of Qiqihar, No. 333 Bukui North Road, Jianhua District, Qiqihar City, \\ Heilongjiang Province 161006, P.R. China \\ ${ }^{3}$ College of life Science and Agriculture Forestry, Qiqihar University, Qiqihar City, Heilongjiang \\ Province 161006, P.R. China \\ ${ }^{4}$ Third Affiliated Hospital of Qiqihar Medical University, Qiqihar City, Heilongjiang Province \\ 161006, P.R. China \\ *E-mail: 363046903@qq.com
}

doi: $10.20964 / 2017.04 .66$

Received: 24 January 2017 / Accepted: 3 March 2017 / Published: 12 March 2017

\begin{abstract}
An electrochemical immunosensor was studied for sensitive detection of Ki-67 protein based on a dual amplification mechanism resulting from Au nanoparticles (AuNP)-polydopamine (PDA) as the sensor platform. By utilizing PDA, biomolecules was immobilized for both the construction of the sensor platform and the signal labeling. The particular platform of AuNP-PDA, as well as synthesizing horseradish peroxidase (HRP)-antibody (Ab2) functionalized AuNP-PDA@ graphene was utilized to immensely enhance the sensitivity. The amperometry determination was used to obtain a linear response range of $\mathrm{Ki}-67$ which was from 4 to $800 \mathrm{pg} / \mathrm{mL}$, along with a very low detection limit (1.7 $\mathrm{pg} / \mathrm{mL}$ )
\end{abstract}

Keywords: Pancreatic neuroendocrine tumor; Ki-67; Immunosensor; Polydopamine; Graphene

\section{FULL TEXT}

(C) 2017 The Authors. Published by ESG (www.electrochemsci.org). This article is an open access article distributed under the terms and conditions of the Creative Commons Attribution license (http://creativecommons.org/licenses/by/4.0/). 